with workers born in India having a lower probability of being exposed (Predicted probability of exposure:. 50 (95\% CI. $46, .54)$ compared with the other migrant workers.

Discussion High strain jobs adversely affected wellbeing independent of migrant status. Job strain was not associated with either exposure to carcinogens or migrant status. However migrant status was associated with exposure to carcinogens.

\section{C.5 PRECARIOUS WORK AND PRECARIOUS LIVES: AN ANALYSIS OF THE ASSOCIATION BETWEEN EMPLOYMENT RELATIONSHIPS AND ACCESS TO SOCIAL AND HEALTH BENEFITS}

Mieke Koehoorn*, Robert Macpherson, Christopher B McLeod. University of British Columbia, Vancouver, Canada

\subsection{6/OEM-2019-EPI.100}

Background Precarious employment relationships impact many facets of society, among them health and health inequities for workers and their families. The objective of the current analyses was to investigate the association between precarious employment and access to social and health employment benefits in the Canadian context.

Methods The General Social Survey (GSS) is an annual and national cross-sectional survey administered by Statistics Canada. The GSS2016 focused on social trends in education, work and home conditions to inform policy issues. The association between employment status (regular versus seasonal, term, casual) and access to employment benefits (pension, sick leave, vacation, disability, workers' compensation, parental leave, supplemental medical, and other) was investigated using multivariable logistic regression, adjusted for socio-demographic (age, sex, education, visible minority, immigrant), occupation and industry, and physical and mental disability characteristics.

Results Among those employed at the time of the survey (60.4\% of 19609 respondents), the majority had regular $(80.8 \%)$ versus precarious seasonal $(7.0 \%)$, casual $(6.9 \%)$, or term (5.3\%) employment. Twenty-eight percent of precarious workers reported no employment benefits compared to $6 \%$ of regular workers (ORadj=4.99, 95\% CI 3.53, 7.05). By type of benefit, the greatest disparity between precarious employment and no benefits was reported for disability insurance (ORadj=2.45 95\% CI 1.81, 3.32) and supplemental medical benefits (ORadj=2.54 95\% CI 1.90, 3.38), while the least disparity was reported for workers' compensation benefits (ORadj=1.46 95\% CI 1.11, 1.92).

Discussion Precarious work may equate to precarious living for a significant number of workers without pension, disability, sick leave, family or medical employment benefits. The impact of the observed disparity in employment benefits for workers with regular versus precarious attachment to the labour market warrants longer-term investigation, but the findings suggest that precarious work could be a significant social determinant of health.

\section{C.6 'HEALTHY ON THE OUTSIDE, SICK ON THE INSIDE' - FORESTRY WORKERS, EMBODIMENT AND BIOSOCIALITY}

Kirsten Lovelock*. Worksafe, Wellington, New Zealand

10.1136/OEM-2019-EPI.101
Health outcomes for workers in forestry are shaped by a complex range of exposures, including exposures related to the work environment generated by the industry itself and within a natural environment. We understand how the worker experiences these exposures is shaped by a range of contextual factors including external factors such as market prices and legislation; employer specific factors (e. g. pace of work, provision of Personal Protective Equipment (PPE)); to task specific factors (e.g. repetition, worker control). And, health outcomes from these exposures can range from immediate to delayed, and in duration from acute to chronic. This paper draws on a qualitative research project conducted with forestry workers, their contractors and the CEOs of corporate forests in New Zealand and argues that we need to know more if we are to intervene effectively. Face to face interviews and focus groups were conducted with 100 participants at multiple sites throughout New Zealand (Northland, Gisborne, Central North Island, Hawkes Bay, Wanganui and Otago). This paper focuses specifically on the experiential aspects of being a forestry worker and contractor and how the concept of embodiment and bio-sociality is a useful means by which to understand how bodies are produced and reproduced through labour, how labour converts bodies into social entities and that the body is not exclusively in either the biological or social world, rather bodies are made, have social value and the sociality of bodies shapes altered biologies. These concepts allow us to understand why it is that workers self-describe and are described as being 'healthy on the outside, sick on the inside' or 'fit on the outside, sick on the inside' and to unpack how social groups form around biological identities marked by ill health or illness susceptibility.

\section{Chemical and Physical Hazards}

\section{D.1 LONGITUDINAL ANALYSIS OF INCIDENCE OF BERYLLIUM SENSITIZATION IN A US NUCLEAR WORKFORCE}

${ }^{1}$ Ashley Golden*, ${ }^{2}$ Miranda Dally, ${ }^{1}$ Jeffery Miller, ${ }^{2}$ Lee Newman, ${ }^{1}$ Donna Cragle. 'ORAU, Oak Ridge, USA; ${ }^{2}$ Colorado School of Public Health, Aurora, USA

\subsection{6/OEM-2019-EPI.102}

The goal of this study was to evaluate trends in incidence of beryllium sensitization $(\mathrm{BeS})$ and the impact of exposure regulation in a US Department of Energy (DOE) nuclear worker cohort. The 1999 DOE final rule for Chronic Beryllium Disease Prevention Program was established to accomplish three goals: reduce the number of workers currently exposed to beryllium; minimize exposures and the potential for exposure; and establish medical surveillance requirements to ensure early detection of disease. While the impact of this rule has been evaluated through observational reports, with decreases in exposure and reported cases, there have been no published studies assessing whether exposure reduction measures result in the prevention of BeS.

Methods We examined the incidence of beryllium sensitization in a cohort of 6915 workers with almost 29,000 BeLPT results obtained between 1994-2018. All workers 